reflection was deemed particularly useful with the timing of revalidation and encouraging reflection on practice from day one.

It continues to be an evolving document, as new feedback is received and research published, the pack is regularly adapted to meet the needs of our new staff. Considering transferability, we have already witnessed that it has been so well accepted that, we are making it available to all nursing staff to help assist them with self-development.

\section{P-225 AN OBSERVATIONAL EXCHANGE PROGRAM BETWEEN HOSPICE AND ACUTE STAFF}

'Jude Edwards, 'Suzie Doe, ${ }^{2}$ Susan Heatley. 'St Ann's Hospice, Cheadle, UK; ${ }^{2}$ Manchester Royal Infirmary, Central Manchester University Hospitals

10.1136/bmjspcare-2016-001245.246

Background The complexity of patients in the hospice has significantly increased over the last five years, and includes non-cancer diagnoses. There is an increasing number of patients who are now admitted to hospices with a non-cancer diagnosis e.g. COPD, end stage heart and renal disease. Patients who are transferred from hospitals to hospices have increasingly more diverse and specific treatment regimes.

Why it is important? The 2016 End of Life Care audit in hospitals acknowledges that there has been steady progress in the care of dying people since the previous audit carried out in 2013 and published in 2014. However as in the past the provision for palliative care is inconsistent across the country, this is particularly true of out of hours. Although it is unfair to directly compare hospices and hospitals, the advantages of sharing specific knowledge and skills across the two is clear.

What is currently being done? A one-week nurse exchange; centred on observations, is agreed between St Ann's Hospice and the Renal, Cardiology, Haematology and Respiratory departments of Central Manchester Foundation Trust. Discussions are underway to include Gastro-enterology. The programme adopts a hands-on approach where knowledge and skills are shared through shadowing and observations.

Evaluation Following on from the renal exchange programme last year, a new evaluation form has been produced that captures the data in a more quantitative manner, thus allowing outcomes to be more auditable.

Overall objectives

1. Equip St Ann's staff with the skills and knowledge to deal with more clinically complex patients

2. Raise awareness of individualised end of life care in a hospice setting.

The future This is an ongoing project, aiming to cascade across all hospital specialities, with a view to develop end of life care 'Champions' in each speciality. Our goal would be to see this partnership program replicated in other organisations.

\section{P-226 STORYBOARDING AS AN AID TO LEARNING ABOUT DEATH SITUATIONS IN CHILDREN'S NURSE EDUCATION}

Yvonne Dexter. University of West London, London, UK

\subsection{6/bmjspcare-2016-001245.247}

Although UK child death rates are falling (ONS 2015) their impact is out of proportion to their incidence in relation to the number of people affected and the severity of their effects (Hindmarch,
2009). The intensity of caring for children and families in death situations is known to have an impact on health care practitioners, both painful and rewarding (Papadatou 2009). Caring for dying children is one of the most challenging and unique experiences that student nurses experience while on placement in a variety of settings including hospitals, hospices and the community. Death education for nurses has been studied but there has been limited research into the preparation of those working with dying children and its effectiveness in preparing them for this role (Malloy et al., 2006; Carson 2010). This provides children's nurse educators with a challenge and opportunity to be innovative. Rather than relying on didactic methods when teaching loss issues to student nurses, educators should use creative, interactive and experiential approaches (Matzo et al., 2003; Carson 2010). Narrative pedagogy is appropriate for death education building on a common strategy for nurses caring for children and families in death situations where sharing experiences with colleagues and gaining emotional support is seen as a positive way to learn to manage grief and construct meaning (Keene et al., 2010). Storyboarding is an educational technique that has been used to facilitate narrative and reflection in nurse education (Lillyman et al., 2011; Lillyman and Bennett 2012). It "offers an engaging visual approach to narrative that is both simple and effective" (Johns 2013, p.260). This presentation will share experiences of using storyboarding with children's nursing students as an aid to reflection on death situations that they have experienced in practice and as a means of bridging the gap between theory and practice.

\section{P-227 PRACTICE EDUCATORS - THE DUAL PROFESSIONALS}

Mandy Motley. LOROS, Leicester, UK

\subsection{6/bmjspcare-2016-001245.248}

The role of practice educators within hospices is a crucial one. They are instrumental in developing their own workforce, but they also make a significant contribution to the development of the wider health and social care workforce in their locality. The staff who carry out this role are highly qualified and experienced professionals from various specialisms, nursing, social work, chaplaincy and many others.

One of the challenges of the practice educator is the lack of access to suitable teaching and learning programmes. Over the past 12 months in the East Midlands we have worked on an innovative model of collaborative working, with three hospices (LOROS, Cynthia Spencer and St Barnabas) working together with a training provider to develop a bespoke programme which meets that challenge.

Nine staff have engaged in a combined programme which leads towards a certificate in teaching and learning, an assessor qualification and a quality assurance qualification. The formal face-to-face learning is a five-day programme, delivered over a period of six months, the sessions were hosted at the three different hospices. Each individual staff member was able to identify their own programme outcomes depending on their needs.

A number of staff are working towards all three qualifications, with others opting to achieve just one or two. The flexibility of the programme has meant that the needs of the organisations are being met, by building capacity for assessment and quality assurance, as well as the needs of the individuals to extend their knowledge and understanding of their second profession - teaching and facilitating learning. 